\title{
Olefin metathesis of fatty acids and vegetable oils
}

\author{
VYSHNAVI YELCHURI, K SRIKANTH, R B N PRASAD and M S L KARUNA* \\ Centre for Lipid Science and Technology, CSIR- Indian Institute of Chemical Technology, Hyderabad 500007 , \\ India \\ E-mail: mslkaruna@gmail.com; karuna@iict.res.in
}

MS received 12 October 2018; revised 27 February 2019; accepted 9 March 2019; published online 4 May 2019

\begin{abstract}
The article reviews various olefin metathesis reactions namely self-metathesis (SM), crossmetathesis (CM), acyclic diene metathesis (ADMET) polymerization, ring closing metathesis (RCM) and ring opening metathesis (ROM) reactions for the synthesis of a variety of platform chemicals with potential industrial applications from vegetable oils and fatty acids. Different fatty acids employed for various metathesis reactions were oleic, linoleic, linolenic, eicosenoic, erucic, petroselinic, sterculic, undecenoic and ricinoleic acids, while vegetable oils used were Helianthus (sunflower), Brassica napus (rapeseed), Glycine max (soybean), Hevea brasiliensis (rubber), Butea monosperma (palash), Nicotiana tabacum (tobacco) and Sterculia foetida (jangli badam). Even though Grubbs' catalysts were employed for most of the reactions, other catalysts such as rhenium, molybdenum and tungsten based have also been used for selective reactions of vegetable oils and fatty acids. The article reviews some of the mechanistic pathways involved in the generation of unusual intermediates from fatty acids and triglycerides.
\end{abstract}

Keywords. Olefin metathesis; vegetable oil; fatty acid methyl ester; self-metathesis; cross-metathesis; ring closing metathesis; ring opening metathesis.

\section{Introduction}

With the depletion of fossil fuels and increasing emission of greenhouse gases, the importance of renewable raw materials has been increasing by the day and sustainable development has become a key ideal of the 20th century. ${ }^{1}$ The utilization of renewable raw materials can meet the principles of green chemistry such as built-in design for degradation or low toxicity of the resulting products. ${ }^{2}$ Vegetable oils with unsaturated fatty acids form promising, renewable and cheaper feedstocks for generating a number of oleo chemicals to develop a sustainable future. ${ }^{3-6}$ Numerous fatty acids are today available which makes them attractive for synthesis and as raw materials for the chemical industry. ${ }^{5}$ Hitherto, industrial oleo chemistry has concentrated predominantly on the carboxyl functionality of fatty acids but, more recently, modern synthetic methods have been applied extensively to fatty compounds for the selective functionalization of the alkyl chain. ${ }^{5}$ Radical, electrophilic, nucleophilic and pericyclic as well as transition metal catalyzed additions to the $\mathrm{C}-\mathrm{C}$ dou-

\footnotetext{
*For correspondence
}

ble bond, as seen in case of oleic acid, an unsaturated fatty acid, is readily accessible to a large number of novel fatty compounds with many interesting properties. Reports say that $90 \%$ of the oleo chemical reactions are derived by the modification at the fatty acid carboxylic group and less than $10 \%$ by transformations of the alkyl chain. However, future technologies on the development of various industrial chemicals depend on the modification of the alkyl chain. Hence, oils and fats offer possibilities for providing chemistry with a wealth of reaction products which are of great value in the future by conducting a number of organic reactions across the double bonds of vegetable oil fatty acids like oxidations, reductions, polymerizations, ${ }^{5,7}$ etc. However, olefin metathesis has been a modern versatile tool for the functionalization of plant oil derived chemical intermediates. The approach contributes to sustainable development and reduction in $\mathrm{CO}_{2}$ emission as the raw materials employed are safer, and less toxic. Metathesis reactions involve redistribution of fragments of alkenes by scission and regeneration of $\mathrm{C}-\mathrm{C}$ double bonds (Figure 1). ${ }^{8,9}$

Depending on the participation of the unsaturated fatty acids, metathesis reactions can be classified into self-metathesis (SM), cross-metathesis (CM), 
ring-closing metathesis (RCM), ring-opening metathesis $(\mathrm{ROM})$, ring-opening metathesis polymerization (ROMP) and acyclic diene metathesis polymerization (ADMET) (Figure 2).

The mechanism for the olefin metathesis reaction was proposed by Chauvin (Figure 3). This involves a [2+2] cycloaddition of an alkene double bond to a transition metal alkylidene to form a metallacyclobutane intermediate, which then breaks up in the reverse approach to give a new alkylidene and a new olefin and the process is repeated sufficiently till an equilibrium mixture of olefins are obtained.

Transition metal catalyzed metathesis ${ }^{9-16}$ of olefins is used in petrochemistry and polymer chemistry for the production of special olefins and is applicable to unsaturated fatty acid esters. Metathesis of oil-based feedstocks such as vegetable oil, fish oil and animal fat leads to a number of industrially important chemicals e.g: waxes, plastics, cosmetics, biofuels, etc. ${ }^{6}$ The researchers have employed different homogenous and heterogeneous catalysts like ruthenium-based, ${ }^{17}$ molybdenum ${ }^{18}$ tungsten $^{16}$ and rhenium-based ${ }^{19-22}$ for metathesis reactions. Further, the researchers also observed that good conversions were obtained using high catalyst loadings. However, modern heterogeneous catalysts namely Grubbs' first and second generation catalysts, Hoveyda-Grubbs catalyst (Figure 4) were

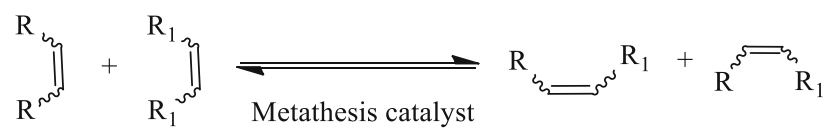

Figure 1. Olefin metathesis.

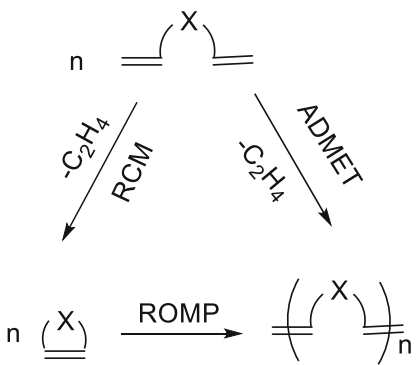

found to be more efficient in generating platform chemicals which can replace most of the petroleum-based chemicals. ${ }^{23}$ Grubbs' first and second generation catalysts are used in organic synthesis as the first generation catalysts with higher activity. Recent advances in the development of metathesis catalysts in the Grubbs' group resulted in a family of ruthenium carbene catalysts which have significant advantages over the traditional tungsten based catalysts. ${ }^{24}$ Grubbs' catalysts were shown to be insensitive to the presence of oxygen, and with the modifications to the ligand system, these catalysts were actually shown to be active in water. ${ }^{25}$

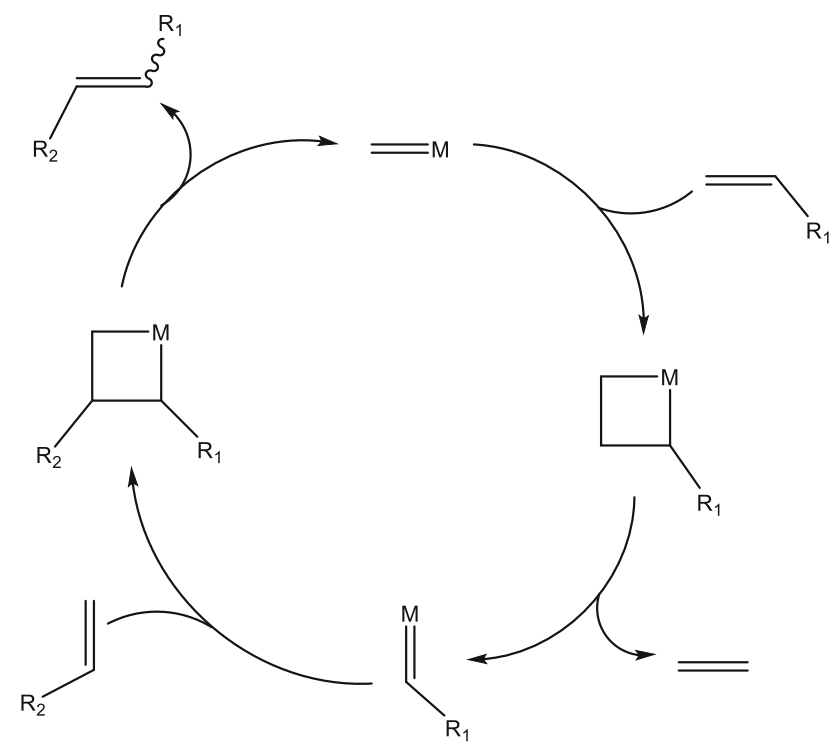

Figure 3. Chauvin mechanism for olefin metathesis reaction.

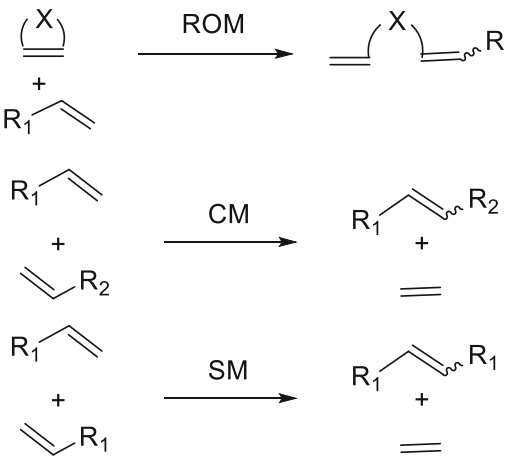

RCM-Ring Closing Metathesis, ADMET-Acyclic Diene Metathesis, ROM-Ring Opening Metathesis, ROMP-Ring Opening Metathesis Polymerization, CM-Cross Metathesis, SM-Self Metathesis

Figure 2. Types of olefin metathesis reactions. 


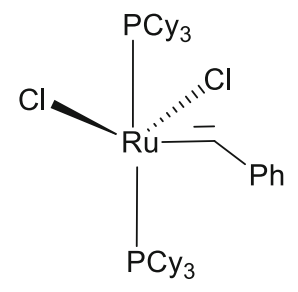

First-generation Grubbs catalyst

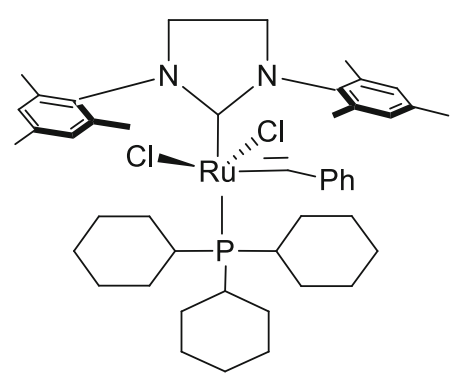

Second-generation Grubbs catalyst

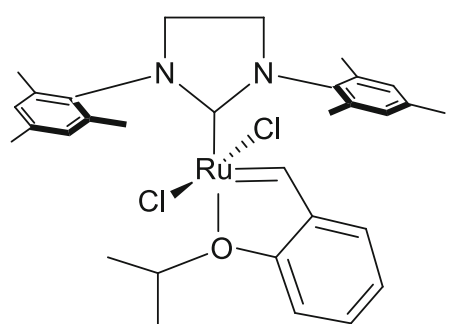

Hoveyda-Grubbs catalyst

Figure 4. Structures of Grubbs' first, second generation and Hoveyda catalysts.

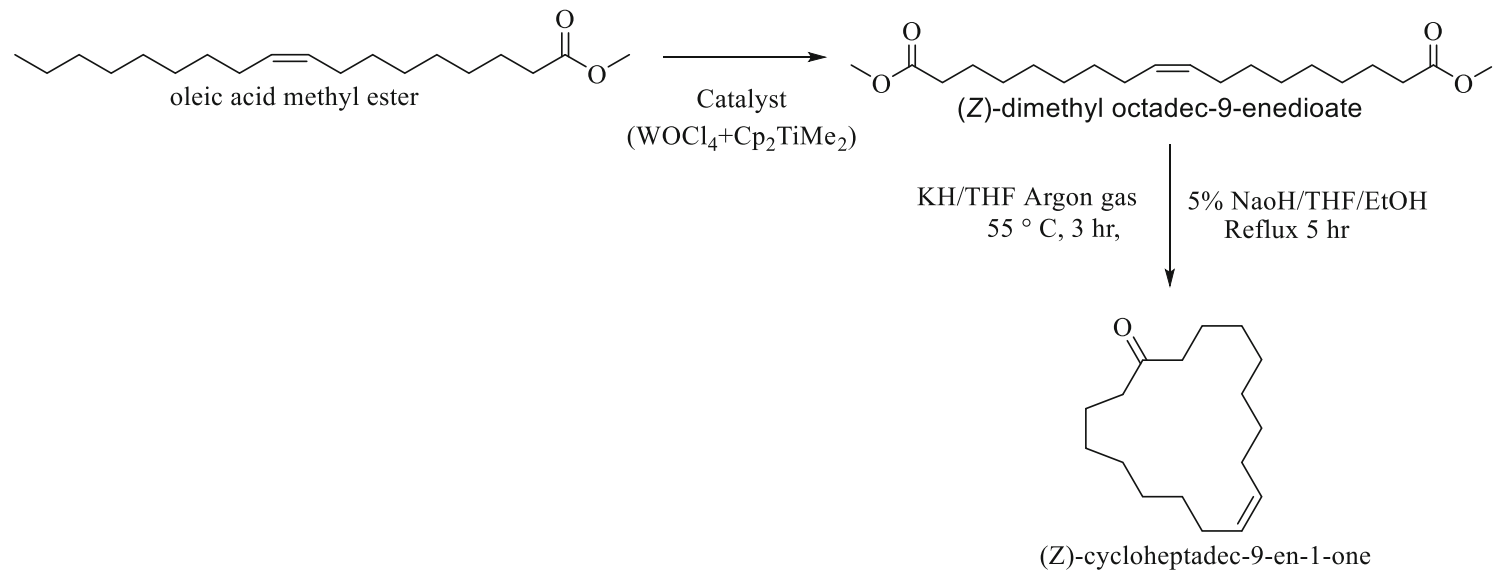

Figure 5. Synthesis of (Z)-cycloheptadec-9-en-1-one (civetone).

The article reviews the various metathesis reactions and catalysts used to generate platform chemicals useful for a number of industrial applications.

\subsection{Self-metathesis (SM)}

Metathesis reaction in which both double bonds are part of the same molecule is termed as self-metathesis.

1.1a Self-metathesis of fatty acids: Self-metathesis of long-chain unsaturated fatty acid esters was first reported by Boelhouwer and co-workers. ${ }^{26}$ This route in the presence of a suitable catalyst provides a convenient and highly selective route to produce unsaturated diesters, high-value intermediates for a number of oleo chemicals. Self-metathesis of the following fatty acids or their esters was carried out to develop a variety of platform chemicals.

The most studied fatty acid ester is methyl oleate (methyl cis-9-octadecenoate), an ester of oleic acid, a readily available naturally occurring fatty acid. Methyl oleate upon metathesis yields $50 \%$ (equilibrium conversion) of 9-octadecene (a lube oil range hydrocarbon intermediate) and dimethyl 9-octadecendioate (used for the production of macrocyclic compounds). The diester of methyl or ethyl oleate on subjecting to Dieckmann condensation leads to cycloheptadec-9-en-1-one (civetone), an important base material used in the perfumery industry (Figure 5). ${ }^{27-29}$

Self-metathesis of many long-chain unsaturated fatty acids such as methyl elaidate, methyl 11-eicosenoate, methyl palmitoleate, methyl vaccinate, methyl erucate (major fatty acid of high erucic rapeseed oil and crambe oil), methyl petroselenate (major fatty acid of coriander oil) and methyl 5-eicosenoate (methyl gadoleate, major fatty acid of meadow foam oil), methyl ricinoleate (major fatty acid of castor oil), methyl undecenoate (second generation product of castor oil) and long chain fatty acids such as methyl oleate was carried out (Figure 6). The various intermediates produced from these sources are polyenes, monoesters, diesters and cyclopolyenes. ${ }^{30}$ Ricinoleic acid, a hydroxyl fatty acid present in 87-90\% in castor oil upon self-metathesis leads to dihydroxy unsaturated hydrocarbon and an unsaturated diester. ${ }^{31}$ Also, the second generation product of castor oil, undecenoic acid upon self-metathesis leads to unsaturated diester. ${ }^{32}$ These molecules with unusual chain lengths and functionalities which are otherwise difficult to be synthesized by conventional methods can be obtained by employing metathesis route. These can be exploited 


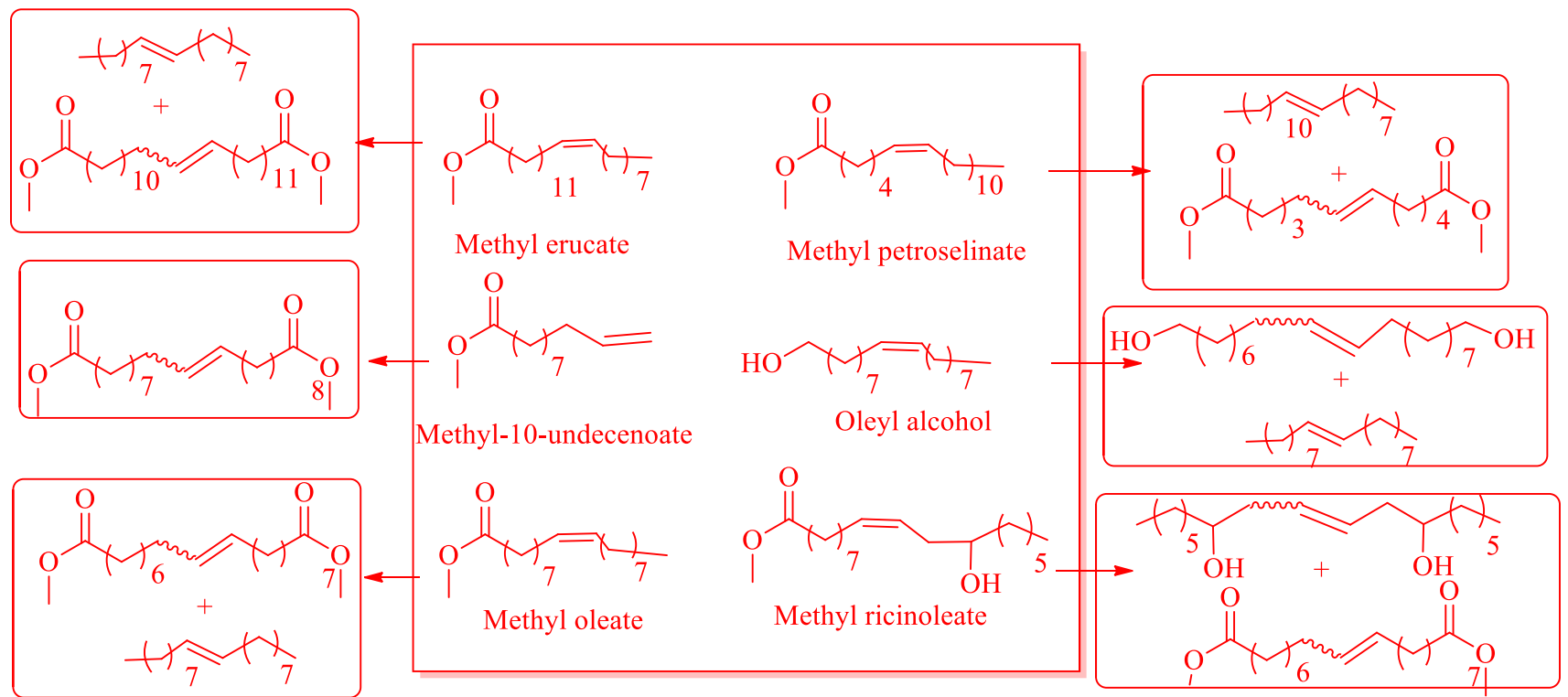

Figure 6. Self-metathesis of fatty acid methyl esters.

for lubricant, surfactant and other polymeric applications.

The effect of Grubbs' second-generation catalyst on the product formation was studied by Vyshnavi et al., varying the catalyst concentrations from 0.03 mmol to $0.18 \mathrm{mmol}^{33}$ At $0.06 \mathrm{mmol}$ concentration only two products namely 9-octadecene and dimethyl-9octadecenedioate were observed. Lower and higher concentrations resulted in more number of products such as cyclopropaneoctanoic acid methyl ester, 11-eicosenoic acid methyl ester, methyl-9-octadecenedioate, and 9octadecene. Hence, the desired products can be synthesized by manipulating the catalyst concentration.

\subsection{Cross metathesis (CM)}

Metathesis between two different molecules is termed as cross-metathesis. Cross-metathesis of unsaturated fatty acid esters with alkenes is an elegant way for synthesizing homologues of these esters, extending greater versatility in the field of oleo chemistry.

1.2a Cross-metathesis of fatty acids: Cross metathesis of long-chain unsaturated fatty acids $\mathrm{C}_{16}-\mathrm{C}_{18}$ with lower olefins leads to less abundant medium chain lengths $\mathrm{C}_{10}-\mathrm{C}_{14}$, especially $\mathrm{C}_{12}$, highly demanded compounds in the surfactant industry. For example methyl oleate with 2-butene, 2-pentene and a mixture of 2-hexene and 3-hexene, all giving rise to $\mathrm{C}_{11}-\mathrm{C}_{13}$ esters. ${ }^{34-36}$ Apart from cross metathesis of methyl oleate, cross metathesis of $\mathrm{C}_{4}-\mathrm{C}_{6}$ acids with methyl linoleate and a mixture of $\mathrm{C}_{18}$ unsaturated methyl esters derived from tallow and sunflower, ${ }^{37}$ rapeseed and soybean oils, ${ }^{38,39}$ palm oil ${ }^{40}$ also leads to a mixture of medium chain fatty acids. A pheromone precursor is produced by the cross metathesis of ethyl oleate with 5 -decene. ${ }^{41}$ Ethenolysis, cross metathesis of unsaturated esters with ethene leads to short chain $\omega$-unsaturated fatty acid esters with a broad range of applications, ${ }^{42 \mathrm{a}, \mathrm{b}}$ and is particularly attractive due to low cost and abundant supply of ethylene. ${ }^{43 a, b}$

Ethenolysis of methyl oleate results in methyl 9decenoate, a hypothetical source for the production of a number of polymers and copolymers (Table 1). The yields and selectivity of the ethenolysis products with respect to methyl oleate was studied employing Hoveyda-Grubbs' second-generation catalyst immobilized on silica $\left(\mathrm{HG} / \mathrm{SiO}_{2}\right)$. The ratio of $\mathrm{PC}_{2} \mathrm{H}_{4} /$ methyl oleate influenced the selective formation of methyl-9decenoate and 1-decene proportionately. However, the ratio on higher side deactivated the catalyst. By careful tuning of the conditions, Nieres et al., ${ }^{44}$ observed an optimum ratio of $\mathrm{PC}_{2} \mathrm{H}_{4} / \mathrm{MO}$ as 2.5. Ethenolysis of oleic acid serves as an access to olefin blends with mean chain lengths below 18 carbons while reaction with hex-3-enedioic acid gives unsaturated dicarboxylic acids with adjustable mean chain lengths as major products which is due to isomerisation of the double bonds. ${ }^{45}$ Ethenolysis with high turnover numbers $(340,000)$ has been achieved using Grubbs, CAAC catalyst. ${ }^{46}$ Oleic acid upon cross metathesis with 9-decen-1-ol in the presence of Grubbs' second generation catalyst results in $(E)$-Didec-9-enyl octadec-9-enedioate and branched derivatives with lubricating and wax-like properties. ${ }^{47}$ Another industrially valuable polymer, nylon 12 and nylon 13 were obtained from microalgae by cross 
Table 1. Cross metathesis of vegetable oils and fatty acid.

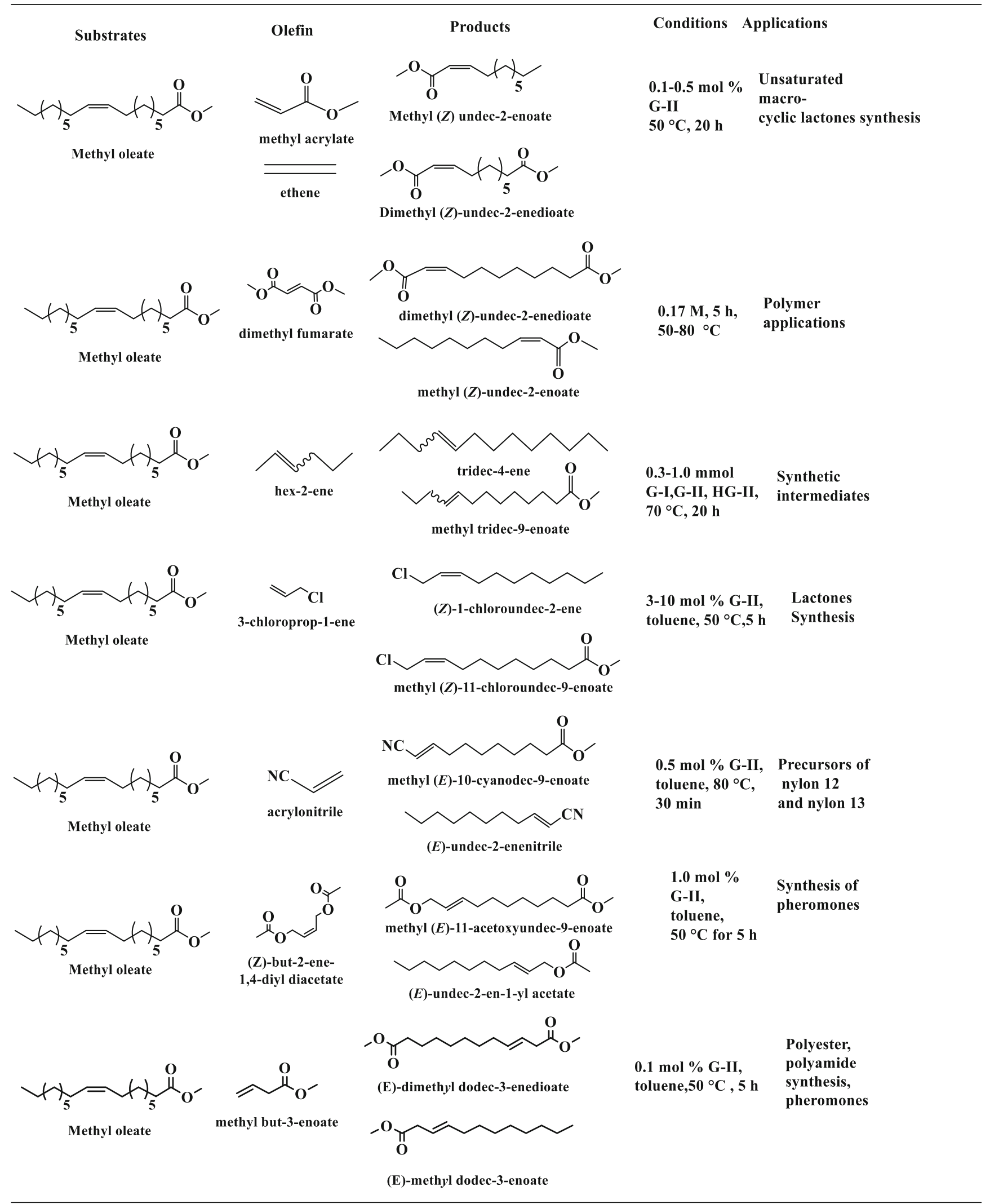


Table 1. (contd.)

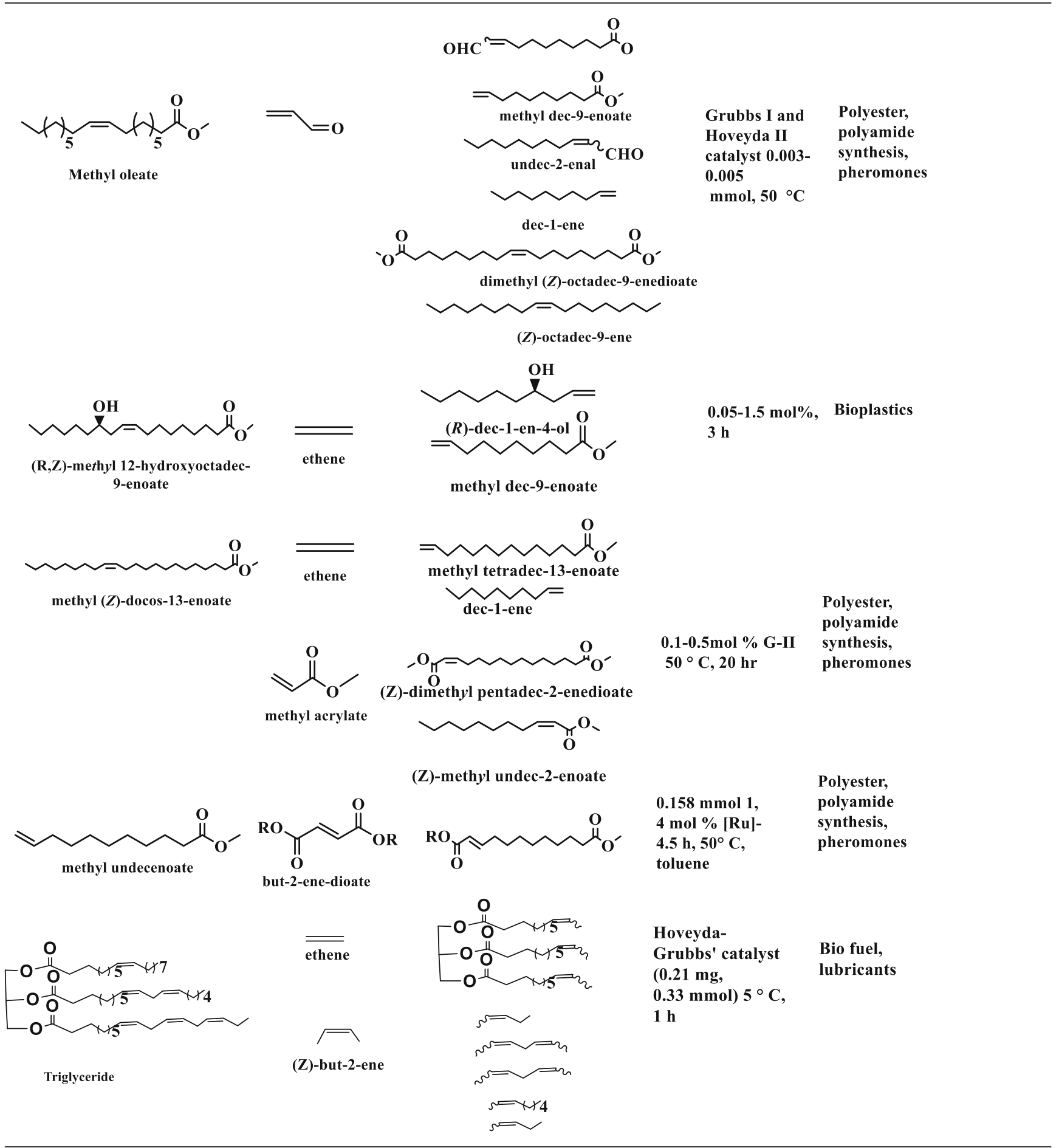

metathesis of methyl oleate with allyl cyanide or homo allyl cyanide with 12-cyano-9-dodecenoate as intermediate (Table 1). ${ }^{48}$ The route was also employed in developing hydrophobizing agents used in the manufacture of lignocelluloses composite products. ${ }^{49}$ High-weight esters $\left(<\right.$ or $\left.=\mathrm{C}_{24}\right)$, acids and their derivatives were prepared from low molecular weight unsaturated esters via cross metathesis of methyl 9-decenoate, used for the preparation of nylon-10. These esters find several polymer applications such as polyurethanes, Nylon -9 , etc. ${ }^{50}$

Long chain di-unsatuarted monoesters were prepared by the cross-metathesis of an unsaturated monoester or diester with cyclic olefins. It also produces long 
chain dicarboxylic acids and diols, fragrances such as 9decen-ol and civetone, ${ }^{51}$ prostaglandins, etc. ${ }^{52}$ Pederson et al. ${ }^{53}$ reported a typical metathesis reaction to yield the pheromone, 11-tetradecenyl acetate from a long chain olefinic ester and 3-hexene catalysed by Grubbs' catalyst. Materia medica, an international drug company has produced pheromones: $(E)-5$-decenyl acetate, a pheromone of peach twig borer (Anarsia lineatella), a mixture of $(E)$-and $(Z)$-11- tetradecenyl acetate of sparganothis fruit worm, pest of cranberries and blueberries employing metathesis route. ${ }^{54}$

Methyl oleate-based estolides and oligomeric base oils were prepared from terminal unsaturated fatty acids by cross metathesis of oleic acid with terminal unsaturated hydrocarbons such as butene catalysed by Grubbs' second generation catalyst (Table 1). ${ }^{55}$ Biokerosene hydrocarbons from $\mathrm{C}_{9}-\mathrm{C}_{16}$ and maleinized ester derivatives were also prepared employing cross metathesis, which are otherwise difficult to prepare using conventional methods. ${ }^{56}$ A number of catalysts were employed for the cross metathesis of unsaturated fatty acid esters for example: Wampler et al., and Bruneau et al., ${ }^{57 \mathrm{a}, \mathrm{b}}$ has conducted a series of metathesis reactions catalyzed by ruthenium alkylidene complex and alkali metals developed by Robert H. Grubbs and also Molybdenum and Tungsten-based catalyst developed by Richard R. Shrock on unsaturated fatty acid esters and vegetable oils to develop diesters and polyol esters. The researchers' observed that TON of the catalyst can be improved by the pretreatment of the substrate, as the contaminants may reduce the efficiency of the catalyst.

On the other hand as pure fatty acids and the catalysts involved are expensive in turn increasing the production cost, attempts were made to prepare the above products taking vegetable oils rich in unsaturation and subjecting them to metathesis employing different catalysts based on Mo and W. ${ }^{58,59}$ Cross-metathesis of triglycerides on butenolysis result in oligomeric and polymeric esters with high viscosity useful for lubricant applications. In this context, the company Elevance Renewable Sciences $180,000 \mathrm{MT}$, a joint venture biorefinery is worth mentioning for its 400 million pounds a year that has been operating in Gresik, Indonesia since 2013. The plant uses a second generation Grubbs catalyst (Figure 4), palm oil and 1-butene, due to its increased solubility and higher catalyst turnover number compared to ethylene. The refinery was initially operated using metathesis of palm oil, and later, on a variety of renewable oil feedstocks such as soybean, mustard, jatropha and algal oils. Metathesis of these oils result in personal care products, detergents and cleaners, lubricants and additives, engineered polymers and other speciality chemical markets. ${ }^{60,61}$ The existing industrial utilization of linear internal olefins in the range of $\mathrm{C}_{11}$ to $\mathrm{C}_{14}$ by Shell Higher Olefin Process result in linear non petroleum derived waxes, while hydrogenation of the entire olefin stream yields n-alkanes $\left(\mathrm{C}_{8}-\mathrm{C}_{18}\right)$ suitable for diesel or jet fuels. ${ }^{62}$ Table 1 shows some of the cross-metathesis reactions employing a variety of molecules, different reactions and different reaction conditions employed and the industrial applications of the products generated.

\subsection{Self and cross-metathesis of vegetable oils}

Self-metathesis of vegetable oils plays a vital role in the polymer industry. Self-metathesis of natural, unsaturated rich fats and oils proceed intra and intermolecularly to produce polymeric glycerides (mainly dimers and trimers). Self-metathesis of plant oils with high unsaturation results in $\mathrm{C}_{18}$ diesters, which on subsequent hydrogenation is converted to diols useful for the synthesis of long-chain polyester in the presence of 1, 5, 7-triazobicyclodecane as catalyst. ${ }^{63}$ Self-metathesis of a mixture of sunflower oil and moringa oil resulted in cyclo-hexa-1, 4-diene, alkenes, mono and dicarboxylic acids. ${ }^{37}$ In the case of soybean, rapeseed, tall oils self-metathesis leads to polycondensation, which in turn results in branching with increased molecular weight, thereby the viscosity and drying properties. ${ }^{64}$

Heterogeneous catalysts $\mathrm{Re}_{2} \mathrm{O}_{7} / \mathrm{SiO}_{2}, \mathrm{Al}_{2} \mathrm{O}_{3} / \mathrm{SnBu}_{4}$ were employed for the metathesis of different fatty acid esters of South African sunflower oil, which resulted in alkene, mono and diesters of varying chain lengths. ${ }^{65}$ Self- metathesis of palm oil was carried out by Nordin et al. ${ }^{66}$ in the presence of homogenous catalysts $\mathrm{WCl}_{6} / \mathrm{Me}_{4} \mathrm{Sn}$ to yield low molecular weight products, 6-pentadecane and 9-octadecene due to the intramolecular reaction between oleate and linoleate chains in the triglycerides. Anti-microbial agents were developed using Copper and Nickel carboxylates of castor seed oilvia metathesis in the presence of ethanol. ${ }^{67}$ Pillai et al., ${ }^{68}$ observed that methyltrioxorhenium (MTO) was a better catalyst for bulky functionalized olefin metathesis such as triglycerols and edible oils compared to Grubbs' second generation catalyst. Unsaturated fatty alcohol alkoxylates were prepared by reducing metathesis-derived monounsaturated alkyl ester of oils followed by alkoxylation of the metathesized esters. These products find an important place as agricultural solvents, non-ionic emulsifiers for agricultural compositions, hard surface cleaners, etc. ${ }^{69}$

Cross-metathesis of fatty oils offers an attractive route for the conversion of long-chain high molecular weight oils into fatty oils of low molecular weight 

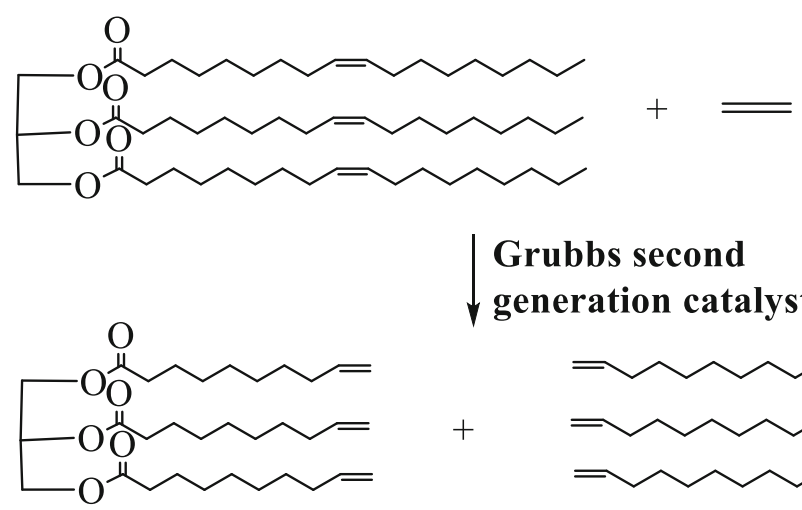

\section{Grubbs second generation catalyst}

Figure 7. Cross metathesis of triolein.

(Figure 7, Table 1). ${ }^{70}$ Ethenolysis of triolein was studied using two catalytic systems $\mathrm{Re}_{2} \mathrm{O}_{7} / \mathrm{Al}_{2} \mathrm{O}_{3}-\mathrm{SnBu}_{4}$ and $\mathrm{Re}_{2} \mathrm{O}_{7} / \mathrm{SiO}_{2} \cdot \mathrm{Al}_{2} \mathrm{O}_{3}-\mathrm{SnBu}_{4}{ }^{37}$ which proceeds via three consecutive metathesis reactions to yield tridecyl glycerol. The second generation ruthenium-based catalysts were found to be the best catalysts to catalyze metathesis reactions involving internal double bonds. ${ }^{71}$ Cross metathesis of vegetable oils such as sunflower, soybean, rapeseed and safflower oils rich in mono-, di-and triunsaturated rich fatty acid chains with an excess amount of olefins like 3-hexene, 5-decene and 7-tetradecene was carried out to produce triglycerides with desirable chain lengths. The triglycerides upon transesterification with ethanol, followed by reduction and on subsequent oxidation or acetylation results in aldehydes or acetates. ${ }^{72}$ Ethanolysis of oils from first generation (rapeseed and sunflower), second generation (waste coffee oil) and third generation (microalgae and yeast) products serve as feedstocks for the production of fuels and chemicals. ${ }^{73}$ Thus, metathesis of biologically sourced oils with ethylene has excellent potential to produce multiple fuels from single oil. Cross metathesis of vegetable oils such as coconut, rapeseed, corn, cottonseed, olive, palm, peanut etc and animal fats with ethylene or butene results in polyol ester oligomers (Figure 7 , Table 1). The oligomers on partial amidation of some of these esters with ammonia or higher organic amines such as dodecyl amine or other fatty amines can be used in personal care formulations (Table1). ${ }^{74}$ Natural oils such as canola oil, rapeseed oil, coconut oil, soybean oil, etc., yellow grease and fish oil-based monomers, dimers, trimers, tetramers, pentamers and higher order oligomer acrylates were prepared to employ the said route. ${ }^{75}$ The polyols synthesized via cross metathesis of 1-butene with palm oil (PMTAG) is mostly employed for the preparation of rigid foams. This route offers an advantage of reducing the dangling chain effects associated with the omega unsaturated fatty acids. ${ }^{76}$
Natural oils were also converted into greases in the presence of metathesis catalysts. ${ }^{77}$ Cross metathesis has been a versatile route in preparing polyethylene mimicking molecules generated by metathesis and copolymerization of fatty acid-based $\alpha, \omega$-dienes. ${ }^{78 a, b}$ Bio-based unsaturated acids were also prepared from octadec-9-enedioic acid in the presence of ruthenium catalysts within $3 \mathrm{~h}$ and in good yields $77 \%$ employing cross metathesis route. ${ }^{79}$ Table 1 shows various products obtained employing cross-metathesis reactions of different triglycerides and their applications. ${ }^{80}$ Cross-metathesis of fatty acid derivatives with reaction partners bearing different functionalities can create a library of internal olefins leading to statistical mixtures of different substituted olefins. ${ }^{81-83 a, b}$ Cross-metathesis has also opened up a new avenue for the synthesis of important peptide-sugar complexes. For example, bioconjugates can be prepared by cross metathesis route taking an amino acid, a fatty acid and a sugar moiety. ${ }^{84}$

Most of the work was carried out either on edible oils or unusual fatty acids/esters. However, in some Asian countries like India, which are importing huge quantities of edible oils and have more than a hundred non-edible oil bearing material containing trees can be exploited in generating a variety of platform chemicals. Some of these sources are rubber, palash and tobacco. In case of rubber ( $80.7 \%$ unsaturation), palash $(65.1 \%$ unsaturation $)$ and tobacco $(88.2 \%$ unsaturation), the oils were found rich in unsaturation and were subjected to self-metathesis employing Grubbs' second generation catalyst. The authors observed that very low concentration of the catalyst $(0.03 \mathrm{mmol}$, based on the weight of the substrate) could bring about metathesis resulting in metathesized products such as cyclodecacyclododecene, 6-pentadecene, 3-dodecene, 9-octadecenoicacid methyl ester, cyclopropaneoctanoic acid methyl ester along with diesters and 9-octadecene for the first time. The possible mechanism involved in the self and cross metathesis of major fatty acid methyl esters such as oleic, linoleic and linolenic acid methyl esters resulting in the above products were also discussed in this study. (Figure 8). ${ }^{85-87}$

Thus, self-metathesis of fatty acids and vegetable oils can be exploited for the generation of alkenes, mono and diesters with high molecular weight intermediates in high TON. The route was employed to prepare methyl oleate with TON 2500 and even 440,000 ${ }^{88 a, b}$ employing Grubbs' first and second generation catalysts. With the advent of development of more and more heterogeneous catalysts, the commercial applications of these reactions can be designed for a wide range of applications. For instance, Materia Inc and Cargill announced the partnership in 2005 to develop metathesis processes for 


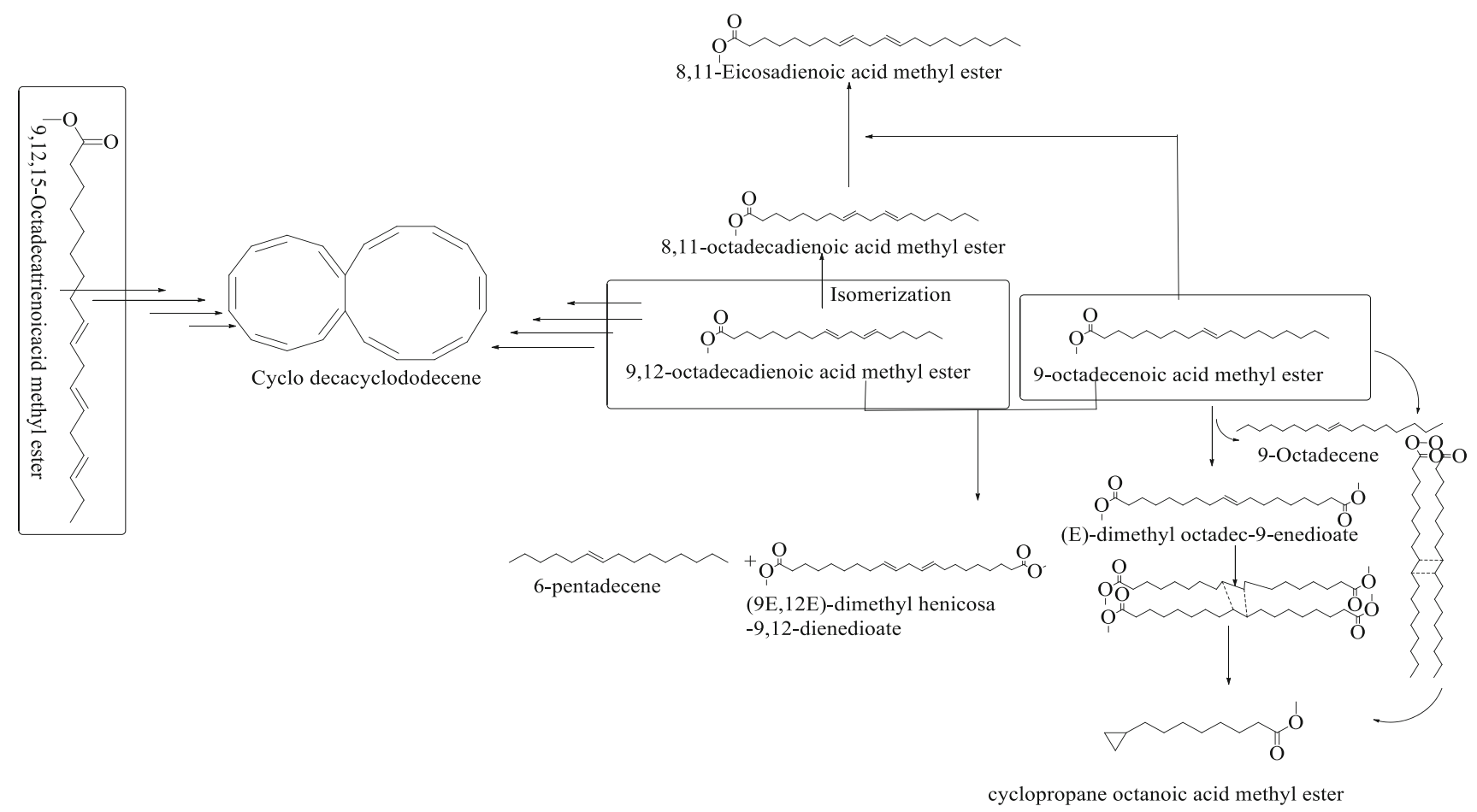

Figure 8. Self and cross metathesis of mixed fatty acid methyl esters prepared from vegetable oils.

converting biobased oils to industrial chemicals, feedstocks and consumer products. ${ }^{89}$

On the other hand, cross-metathesis helps in functionalizing fatty acid derivatives with functional groups ( $\mathrm{ROH}, \mathrm{R}-\mathrm{NH}_{2}, \mathrm{RCO}_{2} \mathrm{H}$, etc.) required for the efficient synthesis of high-value products. It can be a source for multiple fuels from single oil feedstocks, while producing valuable hydrocarbon side products for the polymer industry, forming the basis for a sustainable oil biorefinery.

Another important application of olefin metathesis is polymerization of unsaturated vegetable oils or fatty acids employing ring-opening metathesis polymerization (ROMP) and acyclic diene metathesis (ADMET) polycondensation.

\subsection{ADMET}

Acyclic diene metathesis (ADMET) is a well-defined polycondensation reaction that allows synthesis of unique polymer architectures by simple monomer design, which is not possible using other polymerization methods. ${ }^{90}$ High molecular oligomers can be obtained by acyclic diene metathesis of vegetable oils using Grubbs' ruthenium catalyst, $\left(\mathrm{Cy}_{3} \mathrm{P}\right)_{2} \mathrm{Cl}_{2} \mathrm{Ru}=\mathrm{CHPh}$ (Figure 4) and these can be separated from unreacted oils and lower molecular weight alkene by-products easily. The development of robust metathesis catalysts allowed polymerization of dienic monomers in the

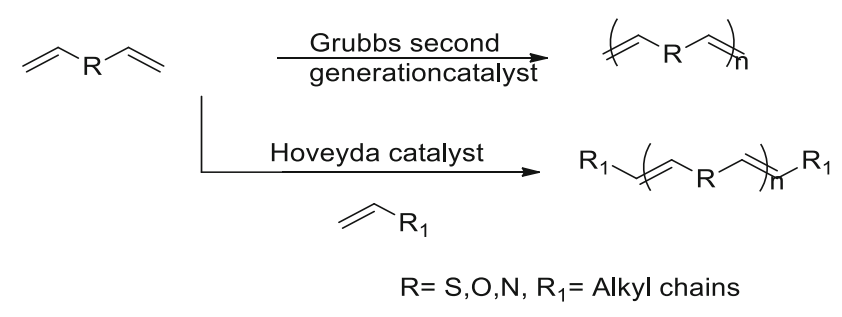

Figure 9. ADMET polymerization of polymerization of $\alpha, \omega$-dienes.

presence of several functional groups very easily. For example, the application of Grubbs' ruthenium catalyst $\left(\mathrm{Cy}_{3} \mathrm{P}\right)_{2} \mathrm{Cl}_{2} \mathrm{Ru}=\mathrm{CH} \mathrm{Ph}$ to the acyclic diene metathesis (ADMET) of vegetable oils resulted in a more environmentally friendly, convenient process to produce metathesized vegetable oils. ${ }^{91}$

ADMET polymerization proceeds in the presence of heteroatoms, as long as the terminal olefins are far away from each other. ${ }^{92}$ ADMET has been extensively used by Wagener since $1987^{93}$ for the synthesis of polyolefins having regularly spaced functional group branches and high thermal stability and crystallinity. ${ }^{94}$ ADMET is also used in preparing a number of polymeric materials containing in-chain functionalities. Many reactions employing ADMET of heteroatom-containing $\alpha, \omega$ dienes, as functionalizing the backbone of the polymers providing different properties (Figure 9) have been reported. ${ }^{95,96}$ 

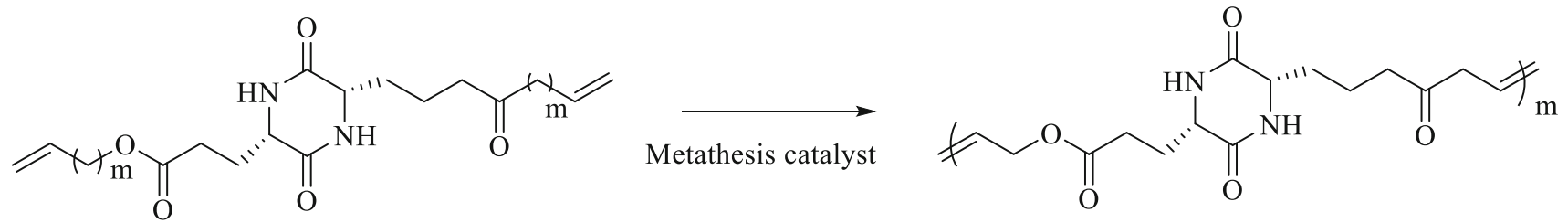

Figure 10. ADMET polymerization of $\alpha, \omega$ dienes containing secondary amides.

For example $\alpha$, $\omega$-dienic monomers containing hydroxyl or phosphorous moieties in addition to ester groups lead to improved flame retardance properties of thermoplastic and thermosetting polyesters. ${ }^{97 a, b, 98}$ Natural plant oils and fatty acids are the most important renewable feedstocks processed in the chemical industry and in the preparation of bio-based functional polymers and polymeric materials. ${ }^{99-101}$ Such monomers with different functionalities were prepared from 10-undecenoic acid and its derivatives employing a three-step procedure. The first step involved reduction of 10-undecenic acid to 10-undecenate followed by condensation of the aldehyde to $\alpha, \omega$ diene under basic conditions. The ADMET polymerization of the monomer, undecenate and allyl alcohol obtained at $80^{\circ} \mathrm{C}$ in the presence of several metathesis catalysts lead to poly allyl alcohols which could be further functionalized or cross linked. Hence, ADMET polymerization plays a key role in the above reaction (Figure 10). ${ }^{102}$

Acyclic diene metathesis (ADMET) has been employed in bulk polymerization of glyceryl triundec10-enoate for producing biorenewable branched polymers. ADMET was also used to polymerize high oleic sunflower oil to afford highly branched and polymerized polyesters. ${ }^{103}$ ADMET polymerization of $\alpha$, $\omega$-dienes containing two secondary amides ${ }^{104}$ (Figure 10) results in polyamides useful for the preparation of a number of oleochemicals. Thus, ADMET is the most efficient method for developing high molecular weight and branched polymers which are otherwise difficult to be produced by conventional methods. The molecular weight of polymers can be varied by varying the ratio of triglyceride used.

\subsection{Ring-opening metathesis polymerization (ROMP)}

ROMP is a type of olefin metathesis chain-growth polymerization, uses strained cyclic olefins to produce stereoregular and monodisperse polymers and copolymers. This provides a wide range of polymers with unique structures and functionalities useful for a number of industrial applications. This type of metathesis converts cyclic olefins into linear polymers containing olefins in the main chain in a three-step process. The first step is the coordination of the cyclic olefin to a metal alkylidene complex, subsequent [2+2] cycloaddition produces a metallacyclobutane intermediate for a growing polymer which undergoes cycloreversion to afford a new metal alkylidene. Strained cyclic olefins having no bulky groups around the double bonds are used as ROMP monomers. The most commonly used cyclic olefin is norbornene and its derivatives due to their high ROMP activity and easy incorporation of substituents on the ring. Norbornene monomers functionalized with a series of fatty acids of chain lengths varying from $\mathrm{C}_{6}-\mathrm{C}_{18}$ were synthesized and polymerized via ROMP in presence of Grubbs' third generation catalyst. ${ }^{105}$ The length of the fatty acid chain strongly determines the terminal properties of the polymers. Some other rings used for ROMP were cyclobutene, cyclopentene and cis-cyclooctene. ${ }^{106,107}$

ROMP are mostly catalyzed using transition metal chlorides as transition metal complex with organic ligands, which helps the reactions to proceed homogenously and are easier to control. In this context, titanacyclobutane complexes are the first examples of single-component catalysts capable of catalysing living ROMP. ${ }^{108}$ On the other hand, titanium and tantalum complex catalysts face limited applicability, as they are incompatible with most heteroatom-containing functional groups. Molybdenum-based alkylidene complexes are also used in ROMP as they are stable towards decomposition and tolerant to a broad range of monomers functionalized with ester, amide, imide, ketal, ether, cyano, trifluoromethyl and halogen groups. Molybdenum catalysts also have the ability to provide stereoregular polymers. The 2,3-disubstituted2,5-norbornadienes polymerize in a living fashion to give highly tactic polymers with $>98 \%$ trans-olefin geometry. ${ }^{103}$ Today a number of metathesis-active $\mathrm{Ru}$ carbene complexes have been developed. Among them, the Grubbs' first generation catalyst synthesized from $\left(\mathrm{PPh}_{3}\right)_{3} \mathrm{RuCl}_{2}$ by the reaction with diazobenzylidene and subsequent phosphine exchange ${ }^{109}$ has been developed as a new class of Ru-based metathesis catalysts. ${ }^{110}$ $\mathrm{a}, \mathrm{b}$ Lactonic sophorolipids are prepared by ROMP. These are a variety of amino acid and peptide-based polymers, which are biocompatible and biodegradable, 


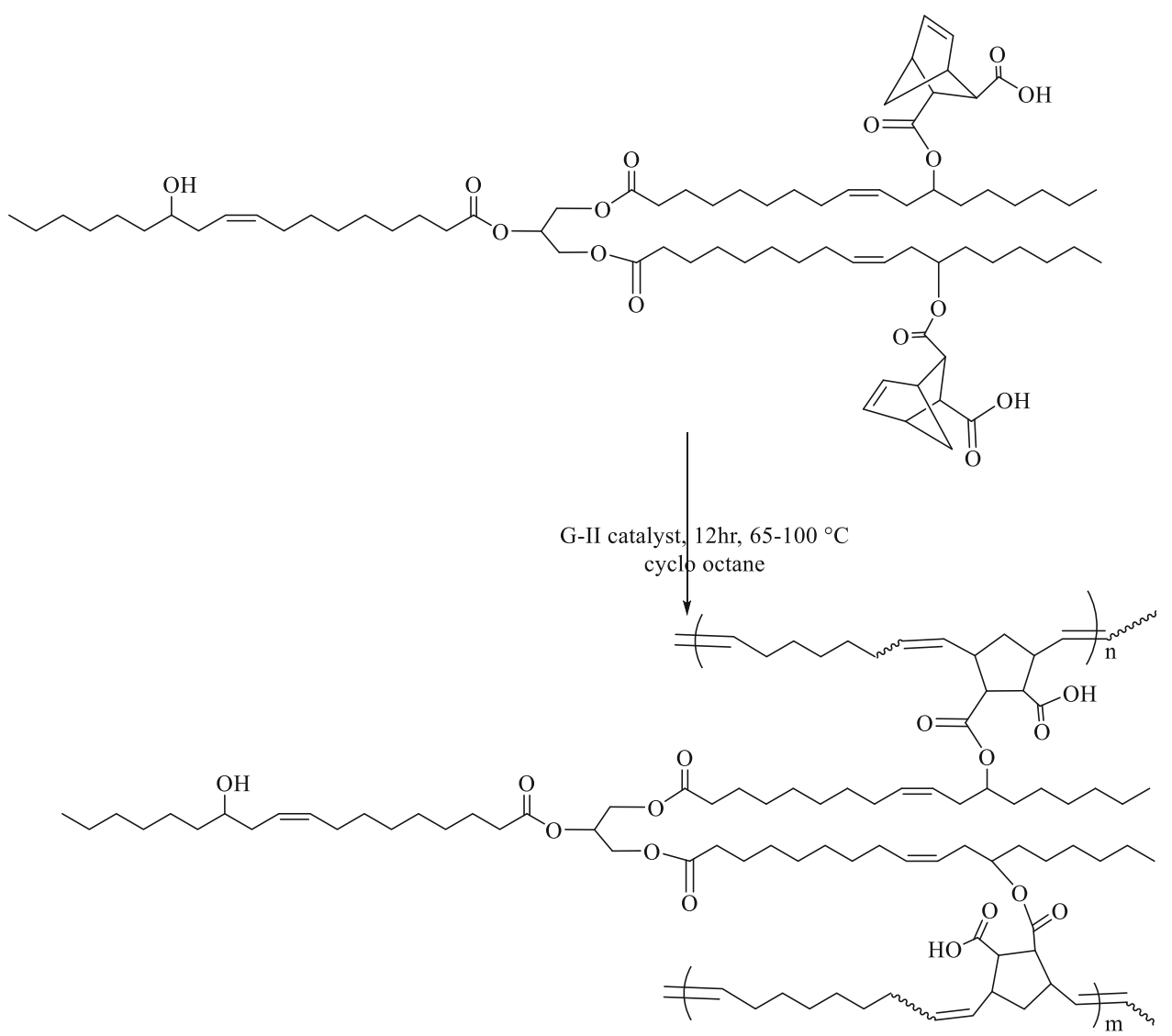

Figure 11. Ring opening metathesis.

are expected to help in building a society with an environmentally sound material-cycle. ${ }^{11,112}$ Polymerizations require compatibility with the polar functional groups of these bioactive ligands. Ru complex catalysts for ROMP are tolerant of various functionalities such as carboxyl, hydroxyl, amide and ester groups. To design artificial analogues to biologically active peptides, an amino acid derived carboxyl groups; ROMP using Grubbs' first-generation catalyst is the best method. ${ }^{113}$

ROMP is mostly employed to develop thermosets. Castor oil containing hydroxy fatty acid, ricinoleic acid $(87-90 \%)$ is the most frequently used substrate to develop thermosets. ${ }^{32,114}$ Castor oil is reacted with commercially available bicyclic anhydride bicycle [2.2.1] hept-5-ene-2,3-dicarboxylic anhydride to give a norborneyl- functionalized bicyclic castor oil derivative (BCO). ${ }^{114}$ Neat BCO undergoes ROMP in the presence of cyclooctene under catalytic conditions affording a transparent rubbery thermoset with $\mathrm{Tg}$ values ranging from 14 to $1{ }^{\circ} \mathrm{C}$. Further norbornenyl- functionalized fatty alcohols derived from soya bean oil and castor oil with fatty acid chains have been used in developing environmentally friendly bioplastics with high performance $^{115}$ (Figure 11). Thus, ROMP plays a very crucial role in developing thermosets with improved thermophysical and mechanical properties with high thermal stabilities.

\subsection{Ring-closing metathesis (RCM)}

RCM is a widely used olefin metathesis route in organic chemistry for the synthesis of various unsaturated rings via intramolecular metathesis of two terminal alkenes, which results in cycloalkene as the $E$ - or $Z$ - isomers. Ethylene is used widely for the preparation of medium-large rings into complex drug molecules, ${ }^{116}$ supra molecular assemblies ${ }^{21}$ or small molecule libraries. ${ }^{117,118}$ Asymmetric RCM reactions ${ }^{18}$ using molybdenum imido-supported alkylidenes offer advantages such as greater activity and superior enantioselectivity. However, most commonly employed catalysts are Grubbs', ruthenium-based catalysts. The later offers high tolerance of functional groups, air stability and easy handling. RCM is usually used in conjugation with other metathesis reactions. For example, some vegetable oils such as algal oils, animal fats, tall oils, canola or soybean oils undergo self, ring opening metathesis, ring-closing metathesis and ADMET to generate fuel range products and intermediates for the preparation of speciality 


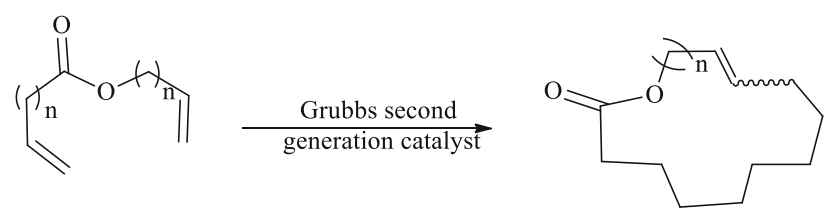

Figure 12. Ring closing metathesis.

chemicals ${ }^{119}$ (Figure 12). Renewable fatty waxes can be prepared by ROMP, RCM of vegetable oils with low molecular weight olefins such as styrene and vinyl cyclohexane. ${ }^{119}$

The approach can be applied in the synthesis of most important perfumery chemicals such as $\gamma$ - and $\delta$ - lactones which are produced in TONS and used in cosmetic industry. These are produced either by chemical synthesis or biotechnological methods which are expensive routes. Thus, this route creates new synthetic opportunities for the incorporation of oleochemicals, as renewable feedstocks into the chemical value chain particularly for the cosmetic industry.

\section{Conclusions}

The review is focused on the importance of various metathesis reactions on vegetable oils and fatty acids and the potential products developed from them. Highly branched, viscous intermediates useful for a number of polymeric and lubricant applications can be produced by self-metathesis of vegetable oils and fatty acids. Cross-metathesis of unsaturated fatty acids with alkenes serves an elegant way for synthesizing homologues of their esters, useful for the preparation of a wide variety of oleochemicals. Cross-metathesis of unsaturated fatty acid esters with ethylene is the most attractive reaction due to low cost. These reactions result in $\omega$-unsaturated fatty acid esters useful for a number of polymeric, lubricant and perfumery applications. Cross-metathesis of vegetable oils results in polyethylene mimicking molecules which are useful intermediates for polymeric applications. Perfumery chemicals, such as civetone and pheromones such as unsaturated fatty acid acetates have been synthesized employing cross metathesis. ROMP (ring opening metathesis polymerization) and ADMET (acyclic diene metathesis) offer a potential route for generating polymeric compounds from unsaturated fatty acids and vegetable oils. ROMP reaction is one of the potential routes for developing thermosets, where castor oil is the most exploited raw material. RCM (ring closing metathesis) and ADMET metathesis are the most employed reactions to generate fuel range products and intermediates. Among the ruthenium, tungsten, molybdenum and rhenium based catalysts, ruthenium-based Grubbs' catalysts are most widely used in the metathesis reactions. Thus, metathesis of vegetable oils and fatty acids is a novel attractive technique that offers possibilities for future developments in the oleochemical industry leading to a sustainable future.

\section{Acknowledgements}

This work was carried with the financial grant given by CSIR and was supported by AcSIR-IICT, India.

\section{References}

1. Eissen M, Metzger, J O Schmidt E and Schneidewind U 200210 years after rio-concepts on the contribution of chemistry to a sustainable development Angew. Chem. Int. Ed. $\mathbf{4 1} 414$

2. Meier M A R, Metzger J O and Schubert U S 2007 Plant oil renewable resources as green alternatives in polymer science Chem. Soc. Rev. 361788

3. Mol J C 1994 Metathesis of unsaturated fatty acid esters and fatty oils J. Mol. Catal. 90185

4. Warwel S, Bruse F, Demes C, Kunz M and Klaas M R G 2001 Polymers and surfactants on the basis of renewable Chemosphere 4339

5. Biermann U, Friedt W, Lang S, Luhs W, Machmuller G, Metzger J O, Rusch Gen Klass M, Schafer H J and Schneider M P 2000 New syntheses with oils and fats as renewable raw materials for the chemical industry Angew. Chem. Int. Ed. 392206

6. Cohen S A, Leutkens M L, Balakrishnan C and Snyer R 2015 Methods of refining natural oil feedstocks $U S$ 8957268 B2

7. Behr A and Gomes J P 2010 The refinement of renewable resources: New important derivatives of fatty acids and glycerol Eur. J. Lipid Sci. Technol. 31112

8. Schwab P, France M B, Ziller J W and Grubbs R H 1995 A series of well defined metathesis catalysts-synthesis of $\left[\mathrm{RuCl}_{2}\left(=\mathrm{CHR}^{\prime}\right)\left(\mathrm{PR}_{3}\right)_{2}\right]$ and its reaction Angew. Chem. Int. Ed. Engl. 342039

9. Mol J C 2002 Application of olefin metathesis in oleochemistry: an example of green chemistry Green Chem. 45

10. Rybak A and Meier M A R 2007 Cross-metathesis of fatty acid derivatives with methyl acrylate: renewable raw materials for the chemical industry Green Chem. 91 356

11. Bazan G C, Oskam J H, Cho H N, Park L Y and Schrock R R 1991 Living ring-opening metathesis polymerization of 2,3-difunctionalized 7oxanorbornenes and 7-oxanorbornadienes by $\mathrm{Mo}\left(\mathrm{CHCMe}_{2} \mathrm{R}\right)\left(\mathrm{NC}_{6} \mathrm{H}_{3}\right.$-iso-Pr2-2, 6) (O-tert-Bu $) 2$ and

$\mathrm{Mo}\left(\mathrm{CHCMe}_{2} \mathrm{R}\right)\left(\mathrm{NC}_{6} \mathrm{H}_{3}\right.$-iso-Pr2-2, 6) $\left(\mathrm{OCMe}_{2} \mathrm{CF}_{3}\right) 2$ J. Am. Chem. Soc. 1136899

12. Calderon N, Chen H Y and Scott K W 1967 Olefin metathesis: A novel reaction for skeletal transformations of unsaturated hydrocarbons Tetrahedron Lett. 8 3327

13. Xia Y, Lu Y and Larock R C 2010 Ring-opening metathesis polymerization (ROMP) of norbornenylfunctionalized fatty alcohols Polymer 5153

14. Thomas R M, Keitz B K, Champagne T M and Grubbs R H 2011 Highly selective ruthenium metathesis catalysts for ethenolysis J. Am. Chem. Soc. 1337490

15. Rybak A, Fokou P A and Meier M A R 2008 Metathesis as a versatile tool in oleochemistry Eur. J. Lipid Sci. Technol. 110797 
16. Seehof N, Mehler C, Breunig S and Risse W 1992 Transition metal catalysed metathesis polymerizations of partially fluorinated norbornene derivatives $\mathrm{J}$. Mol. Catal. 7653

17. Trnka T M and Grubbs R H 2001 The development of $\mathrm{L}_{2} \mathrm{X}_{2} \mathrm{Ru}=\mathrm{CHR}$ olefin metathesis catalysts: an organometallic success story Acc. Chem. Res. 3418

18. Malcolmson S J, Meek S J, Sattely E S, Schrock R R and Hoveyda A H 2008 Highly efficient molybdenumbased catalysts for enantioselective alkene metathesis Nature $\mathbf{4 5 6} 933$

19. Moulijn J A and Mol J C 1988 Structure and activity of rhenium-based metathesis catalysts J. Mol. Catal. 461

20. Spronk R and Mol J C 1991 Regeneration of rheniumbased catalysts for the metathesis of propene Appl. Catal. 76143

21. Commereuc D 1995 New homogeneous rhenium-based metathesis catalysts as models of the rhenium on alumina heterogeneous catalyst J. Chem. Soc. Chem. Commun. 791

22. Morrison R F, Lipscomb N and Eldridge R B 2014 Rhenium Oxide based Olefin Metathesis Ind. Eng. Chem. Res. 5319136

23. Refvik M D, Larock R C and Tian Q 1999 Rutheniumcatalyzed metathesis of vegetable oils J. Am. Oil Chem. Soc. 7593

24. Conrad J C and Fogg D E 2006 Ruthenium-catalyzed ring-closing metathesis: recent advances limitations and opportunities Curr. Org. Chem. 10185

25. Lipshutz B H and Ghoraib S 2012 Designer-Surfactantenabled cross-couplings in water at room temperature Aldrichim. Acta $\mathbf{4 5} 3$

26. Boelhouwer C and Mol J C 1984 Metathesis of fatty acid esters J. Am. Oil Chem. Soc. 61425

27. Tanabe Y, Makita A, Funakoshi S, Hamasaki R and Kawakusu T 2002 Practical Synthesis of (Z)Civetone Utilizing Ti-Dieckmann Condensation $A d v$. Synth. Catal. 344507

28. Tsuji J and Hashiguchi S 1980 Application of olefin metathesis to organic synthesis. Synthesis of civetone and macrolides Tetrahedron Lett. 212955

29. Furstner A and Seidel G 2000 Ring closing alkyne metathesis: stereoselective synthesis of civetone $J$. Organomet. Chem. $\mathbf{6 0 6} 75$

30. de Espinos L M and Meier M A R 2011 Plant oils: The perfect renewable resource for polymer science $E u r$. Polym. J. 47837

31. Jafarpour L, Heck M-P, Baylon C, Lee H M and Mioskowski C and Steven Nolan P 2002 Preparation and activity of recyclable polymer-supported ruthenium olefin metathesis catalysts Organometallics 21671

32. Mutlu H and Meier M A R 2010 Castor oil as a renewable resource for the chemical industry Eur. J. Lipid Sci. Technol. 11210

33. Vyshnavi Y, Badari R, Prasad N and Karuna M S L 2015 Metathesis of 9-octadecenoic acid methyl ester: diversity and mechanism of product formation at various Grubbs' catalyst concentrations Eur. J. Chem. 6 275

34. Verkuijlen E and Boelhouwer C 1974 Formation of cyclohexane-1,4-diene by metathesis of linoleic and linolenic esters J. Chem. Soc. Chem. Commun. 793
35. Bosma R H A, vanden Aardweg G C N and Mol J C 1983 Heterogeneous metathesis of unsaturated esters using a rhenium-based catalyst J. Organomet. Chem. 225159

36. Warwel S and Deckers A 1989 Olefin-Metathese ungesattigter C18-Fettstoffe Tenside Surfact Det. 26252

37. Marvey B B 2008 Sunflower-based feed stocks in nonfood applications: Perspectives from olefin metathesis Int. J. Mol. Sci. 91393

38. Bengi O O, Topoglu B and Sehitoglu S K 2015 Metathesis reactions of rapeseed oil-derived fatty acid methyl esters induced by monometallic and homo bimetallic ruthenium complexes Eur. J. Lipid Sci. Technol. 117 200

39. Sacristan M, Ronda J C, Galia M and Cadiz V 2011 Phosphorus-containing soybean-oil copolymers: Crossmetathesis of fatty acid derivatives as an alternative to phosphorus-containing reactive flame retardants $J$. Appl. Polym. Sci. 1221649

40. Ahmad F B H, Hamdan S, Yarmo M A and Alimunir A 1995 Co-metathesis reaction of crude palm oil and ethene J. Am. Oil Chem. Soc. 72757

41. Pederson R L and Grubbs R H 2011 Synthesis of 5decenyl acetate and other pheromone components $U S$ 6215019 B1

42. (a) Bosma R H A, van den Aardweg F and Mol J C 1981 Cometathesis of methyl oleate and ethylene: a direct route to methyl dec-9-enoate J. Chem. Soc., Chem. Commun. 1132; (b) Baader S, Podsiadly P E, Cole-Hamilton D J and Goossen L J 2014 Synthesis of tsetse fly attractants from a cashew nut shell extract by isomerising metathesis Green Chem. 164885

43. (a) Sibeijn M and Mol J C 1992 Ethenolysis of methyl oleate over supported Re-based catalysts J. Mol. Catal. 76 345; (b) Julis J, Bartlett S A, Baader S, Beresford N, Routledge E J, Cazin C S J and Cole-Hamilton D J 2014 Selective ethenolysis and oestrogenicity of compounds from cashew nut shell liquid Green Chem. 16 2846

44. Nieres P D, Zelin J, Trasartia A F and Apesteguia C R 2016 Heterogeneous catalysis for valorisation of vegetable oils via metathesis reactions: ethenolysis of methyl oleate Catal. Sci. Technol. 66561

45. Ohlmann D M, Tschauder N, Stockis J-P, Gooben K, Dierker M and Gooben L J 2012 Isomerizing olefin metathesis as a strategy to access defined distributions of unsaturated compounds from fatty acids J. Am. Chem. Soc. 13413716

46. Marx V M, Sullivan A H, Melaimi M, Virgil S C, Keitz B K, Weinberger D S, Bertrand G and Grubbs R H 2015 Cyclic Alkyl Amino Carbene (CAAC) Ruthenium Complexes as Remarkably Active Catalysts for Ethenolysis Angew. Chem. Int. Ed. Engl. 541919

47. Bouzidi L, Li S, Di Biase S, Rizvi S Q and Narine S S 2013 Lubricating and waxy esters. 4. Synthesis, crystallization behavior, melt behavior, and flow behavior of linear monoesters incorporating 9-decenol and 9-decenoic acid Ind. Eng. Chem. Res. 522740

48. Abel G A, Nguyen K O, Viamajala S, Varanasi S and Yamamoto K 2014 Cross-metathesis approach to produce precursors of nylon 12 and nylon 13 from microalgae $R S C A d v .455622$ 
49. Kamel F 2007 Nanotechnology and its applications in lignocellulosic composites, a mini reviews eXPRESS Polym. Lett. 1546

50. Maisonneuve L, Lebarbé T, Grau E and Cramail H 2013 Structure properties relationship of fatty acid-based thermoplastics as synthetic polymer mimics Polym. Chem. 45472

51. Plugge M F C and Mol J C 1991 A new synthesis of civetone Synlett. 7507

52. Furstner A, Grela K, Mathes C, Christian W L and Lehmann 2000 Novel and flexible entries into prostaglandins and analogues based on ring closing alkyne metathesis or alkyne cross metathesis J. Am. Chem. Soc. 12211799

53. Pederson R L, Fellows I M, Ung T A I, Shihara H and Hajela S P 2002 Applications of olefin metathesis to commercial products Adv. Synth. Catal. 344 728

54. Mukherjee Singh O 2006 Metathesis catalysts: Historical perspective, recent developments and practical applications J. Sci. Ind. Res. 65957

55. Thompson T, Parson K, Bredsguard J and Jeremy Forest J 2013 Processes for preparing estolide base oils and oligomeric compounds that include cross metathesis $U S$ 8580985 B2

56. Brekan J, DiBiase S A, Wang Z, Dalby A and Bertin P 2014 Maleinized ester derivatives US 20140274832 A1

57. (a) Wampler K M, Cohen S A, Frater G E, Ondi L and Varga J 2014 Methods for treating substrates prior to metathesis reactions, and methods for metathesizing substrates US20140275595 A1; (b) Miao X, Malacea R, Fischmeister C, Bruneau C and Dixneuf P H 2011 Ruthenium-alkylidene catalysed crossmetathesis of fatty acid derivatives with acrylonitrile and methyl acrylate: a key step toward longchain bifunctional and amino acid compounds Green Chem. 132911

58. Narine S, Kumar P, Pillai S, Li S, Bouzidi L and Mahdevari A 2018 Metathesized triacylglycerol green polyols from palm oil for use in polyurethane applications and their related properties US10000724

59. Pillai $\mathrm{P}$ K S, Li S, Bouzidi L and Narine S S 2016 Solvent-free synthesis of polyols from 1-butene metathesized palm oil for use in polyurethane foam $J$. Appl. Polym. Sci. 13343509

60. Littich R, Ilseman A, Hategan G, Liang Y, Koers K and Morie-Bebel M M 2014 Bio-based alternatives for silicone and petrochemical emollients from natural oil metathesis $H \& P C$ Today 918

61. Cohen S A, Morie-Bebel M M, Ilseman A D, Bergmann B, Stephen A Dibiase and Christensen S A 2013 WO2013192384A1

62. Lutz E F 1986 Shell higher olefins process J. Chem. Educ. 63202

63. Mutlu H, Hofsab R, Montenegro R E and Meier M A R 2013 Self-metathesis of fatty acid methyl esters: full conversion by choosing the appropriate plant oil $R S C$ Adv. 34927

64. Stempfle F, Ortmann P and Mecking S 2016 Longchain aliphatic polymers to bridge the gap between semicrystalline polyolefins and traditional polycondensates Chem. Rev. 1164597
65. Marvey B B, Kdu Plessis J A and Vosloo H C M, Mol J C 2003 Metathesis of unsaturated fatty acid esters derived from South African sunflower oil in the presence of a $3 \mathrm{wt} \% \mathrm{Re}_{2} \mathrm{O}_{7} / \mathrm{SiO}_{2}-\mathrm{Al}_{2} \mathrm{O}_{3} / \mathrm{SnBu}_{4}$ catalyst J. Mol. Catal. A Chem. 201297

66. Nordin N A M, Yamin B M, Yarmo M A, Pardan K and Alimuniar A B 1991 Metathesis of palm oil J. Mol. Catal. 65623

67. Cohen S A, Luetkens M L, Balakrishnan C R and Synder 2011 WO2011/046872A2

68. Pillai S K, Abidli A and Belkacemi K 2014 Triacylglycerol self-metathesis over highly chemoselective methyltrioxorhenium supported on $\mathrm{ZnCl}_{2}-$ promoted mesoporous alumina Appl. Catal. A. Gen. 479 121

69. Allen D R, Alonso M, Beddaoui M, Bernhardt R J, Brown A, Dong X M, Gorman W, Hutchison J C, Luebke G, Luka R, Luxem F, Malec A D, Masters R A, Murphy D S, Skelton P, Sook B, Spaulding C, Wiester $\mathrm{M}$ and Wolfe P S 2013 Unsaturated fatty alcohol alkoxylates from natural oil metathesis WO 2013162737 Al

70. Mol J C 2004 Catalytic Metathesis of unsaturated fatty acid esters and oils Top. Catal. 2797

71. Samojlowicz C, Bieniek M and Grela K 2009 Ruthenium-based olefin metathesis catalysts bearing $n$ heterocyclic carbene ligands Chem. Rev. 1093708

72. Di B S A, Wampler K M, Allen D R, Bernhardt R J and Littich R 2013 Unsaturated fatty alcohol compositions and derivatives from natural oil metathesis $W O$ $2013163071 \mathrm{Al}$

73. Chinwan D and Pant S 2014 Bioethanol, butanol \& biodiesel from crop residue IJESR 4812

74. Lipic P M, Coffindaffer T W, Kattau N L, Wei K S and Stella Q 2012 Personal care composition comprising metathesized unsaturated polyol esters WO 2013158964 A2

75. Allard M, Rink H-P, Jung W-A and Moebius J 2007 Oligomeric urethane acrylates, their preparation and use US 20090306422 A1

76. Patel J, Elaridi J, Jackson W R, Robinson A J, Serelis A $\mathrm{K}$ and Such C 2005 Cross-metathesis of unsaturated natural oils with 2-butene. High conversion and productive catalyst turnovers Chem. Commun. 445546

77. Firth B E and Kirk S E 2014 Methods for suppressing isomerization of olefin metathesis products, methods of refining natural oils, and methods of producing fuel compositions EP 2794523 A2

78. (a) Van der Meulen I, Gubbels E, Huijser S, Sablong R 1, Koning C E, Heise A and Duchateau R 2011 Catalytic ring-opening polymerization of renewable macrolactones to high molecular weight polyethylenelike polymers Macromolecules 44 4301; (b) Witt T, Häußler M, Kulpa S and Mecking S 2017 Chain multiplication of fatty acids to precise telechelic polyethylene Angew. Chem. Int. Ed. Engl. 567589

79. Goldbach V, Roesle P and Mecking S 2015 Catalytic isomerizing $\omega$-functionalization of fatty acids ACS Catal. 55951

80. Rahim N F A, Kohtaro W, Ariffin H, Andou Y, Hassan M A and Shirai Y 2014 Synthesis of bio-based monomer from vegetable oil fatty acids and design of functionalized greener polyester Chem. Lett. 431517 
81. Behr A and Gomes P J 2011 The cross-metathesis of methyl oleate with cis-2-butene-1,4-diyl diacetate and the influence of protecting groups Beilstein J. Org. Chem. 71

82. Malacea R, Fischmeister C, Bruneau C, Dubois J L, J Couturier and P H Dixneuf 2009 Renewable materials as precursors of linear nitrile acid derivatives via crossmetathesis of fatty esters and acids with acrylonitrile and fumaro nitrile Green Chem. 11152

83. (a) Behr A and Toepell S 2015 Comparison of reactivity in the cross metathesis of allyl acetate-derivatives with oleochemical compounds J. Am. Oil Chem. Soc. 92 603; (b) Miao X, Fischmeister C, Bruneau C and Dixneuf P H 2009 A direct route to bifunctional aldehyde derivatives via self- and cross-metathesis of unsaturated aldehydes ChemSusChem 2542

84. Vernall A J and Abell A D 2004 Cross-metathesis coupling of sugars and fatty acids to lysine and cysteine Org. Biomol. Chem. 22555

85. Vyshnavi Y, Prasad R B N and Karuna M S L 2013 Metathesis of tobacco fatty acid methyl esters: generation of industrially important platform chemicals Ind. Crops Prod. $\mathbf{5 0} 701$

86. Vyshnavi Y, Prasad R B N and Karuna M S L 2014 Metathesis of rubber fatty acid methyl esters: a green approach for generating industrial platform chemicals IJSR 3209

87. Vyshnavi Y, Prasad R B N and Karuna M S L 2014 Synthesis of industrially important platform chemicals, via olefin metathesis of palash fatty acid methyl esters Eur. J. Chem. 5532

88. (a) de Espinosa L M and Meier M A R 2012 Olefin metathesis of renewable platform chemicals Organomet. Renew. 39 1; (b) Chikkali S and Mecking S 2012 Refining of plant oils to chemicals by olefin metathesis Angew Chem. Int. Ed. Engl. 515802

89. Press release by Elevance Renewable Sciences of May, 18,2011

90. Mutlu H, de Espinosa L M and Meier M A R 2011 Acyclic diene metathesis: a versatile tool for the construction of defined polymer architectures Chem. Soc. Rev. 401404

91. Petkovska Violeta I, Hopkins T E, Powell D H and Wagener K B 2005 MALDI-TOF Detection of olefin structural isomerization in metathesis chemistry Macromolecules 385878

92. Lindmark-Hamberg $M$ and Wagener K B 1987 Acyclic metathesis polymerization: The olefin metathesis reaction of 1,5-hexadiene and 1,9-decadiene Macromolecules 202949

93. Wagener K B, Brzezinska K, Anderson J D, Younkin T R, Steppe K and DeBoer W 1997 Kinetics of acyclic diene metathesis (ADMET) polymerization Influence of the negative neighboring group effect Macromolecules 307363

94. Song S-F, Guo Y-T, Wang R-Y, Fu Z-S, Xu J-T and Fan Z-Q 2016 Synthesis and crystallization behavior of equisequential admet polyethylene containing arylene ether defects: remarkable effects of substitution position and arylene size Macromolecules 496001

95. Rybak A and Meier M A R 2008 Acyclic Diene Metathesis with a Monomer from Renewable
Resources: Control of Molecular Weight and One- Step Preparation of Block Copolymers ChemSusChem. 1542

96. Parkhurst R R, Balog S, Weder C and Simon Y C 2014 Synthesis of poly (sulfonate ester)s by ADMET polymerization RSC Adv. 453967

97. (a) Lligadas G, Ronda J C, Galia M and Cadiz V 2010 plant oils as platform chemicals for polyurethane synthesis: current state-of-the-art Biomacromolecules 11 2825; (b) Stempfl e F, Ortmann P and Mecking S 2013 Which Polyesters Can Mimic Polyethylene? Macromol. Rapid Commun. 34 47

98. Menard R, Caillol S and Allais F 2017 Chemoenzymatic synthesis and characterization of renewable thermoplastic and thermoset isocyanate-free poly(hydroxy) urethanes from ferulic acid derivatives ACS Sustain. Chem. Eng. 51446

99. Lligadas G, Ronda J C, Galia M and Cadiz V 2013 Renewable polymeric materials from vegetable oils: a perspective Mater. Today 16337

100. Samarth N B and Mahanwar P A 2015 Modified vegetable oil based additives as a future polymeric material Rev. Open J. Org. Polym. Mater. 51

101. Sun H-S, Chiu Y-C and Chen W-C 2017 Renewable polymeric materials for electronic applications Polym. J. 4961

102. Mutlu H and Meier M A R 2009 Unsaturated PAX, 20 from renewable resources via metathesis and catalytic amidation Macromol. Chem. Phys. 2101019

103. Biermann U, Metzger J O and Meier M A R 2010 Acyclic triene metathesis oligo- and polymerization of high oleic sunflower oil Macromol. Chem. Phys. 211 854

104. Hibert G, Grau E, Pintori D, Lecommandoux S and Cramail H 2017 ADMET polymerization of $\alpha, \omega$-unsaturated glycolipids: synthesis and physicochemical properties of the resulting polymers Polym. Chem. 83731

105. Mutlu H and Meier M A R 2010 Ring-opening metathesis polymerization of fatty acid derived monomers $J$. Polym. Sci. Part A 485899

106. Walker R, Conrad R M and Grubbs R H 2009 The living ROMP of trans-cyclooctene Macromolecules 42599

107. Zuercher W J, Hashimoto M and Grubbs R H 1996 Tandem ring opening-ring closing metathesis of cyclic olefins J. Am. Chem. Soc. 1186634

108. Sutthasupa S, Shiotsuki M and Sanda F 2010 Recent advances in ring-opening metathesis polymerization, and application to synthesis of functional materials Polym. J. 42905

109. Forman G S, McConnell A E, Tooze R P, van Rensburg W J, Meyer W H, Kirk M M, Dwyer C L and Serfontein D W 2005 A convenient system for improving the efficiency of first-generation ruthenium olefin metathesis catalysts Organometallics $\mathbf{2 4} 4528$

110. (a) Love J A, Morgan J P, Trnka T M and Grubbs R H 2002 A practical and highly active ruthenium-based catalyst that effects the cross metathesis of acrylonitrile Angew. Chem. Int. Ed. 41 4035; (b) Pitet L M and Hillmyer M A 2011 Carboxy-telechelic polyolefins by romp using maleic acid as a chain transfer agent Macromolecules 442378 
111. Gao W, Hagver R, Shah V, Xie W, Gross R A, Firat Ilker M, Bell C, Kelly A Burke and Bryan Coughlin E 2007 Glycolipid polymer synthesized from natural lactonic sophorolipids by ring-opening metathesis polymerization Macromolecules 40145

112. Peng Y, Totsingan F, Meier M A R, Steinmann M, Wurm F, Koh A and Gross R A 2014 Sophorolipids: Expanding structural diversity by ring-opening crossmetathesis Eur. J. Lipid Sci. Technol. 1161

113. Li M, Cui F, Li Y, Tao Y and Wang X 2016 Crystalline Regio-/Stereoregular Glycine-Bearing Polymers from ROMP: Effect of Microstructures on Materials Performances Macromolecules 499415

114. Henna P H, Larock R C 2007 Rubbery thermosets by ring-opening metathesis polymerization of a functionalized castor oil and cyclooctene Macromol. Mater. Eng. 2921201
115. Xia Y and Larock R C 2010 Vegetable oil-based polymeric materials: synthesis, properties and applications Green Chem. 121893

116. Shu C, Zeng X, Hao M H, Wei X, Yee N K, Busacca C A, Han Z, Farina V and Senanayake C H 2006 Efficient large-scale synthesis of BILN 2061, A potent HCV protease inhibitor, by a convergent approach based on ring-closing metathesis J. Org. Chem. 717133

117. Nielsen T E and Schreiber S L 2008 Towards the optimal screening collection: A synthesis strategy Angew. Chem. Int. Ed. 4748

118. Waldmann H 2009 Killing 84 birds with one stone Nat. Chem. Biol. 576

119. Firth B, Pease B M, Ilseman A D, Zopp G, Murphy T A, Weitkamp R and Morie-Bebel M 2016 Methods of making high-weight esters acids and derivatives thereof US 9388098 B2 